\title{
Impacts of isomerism (heterotaxy) on birth hospitalization
}

\begin{abstract}
Isomerism, or heterotaxy, impacts 1 in 10,000 live births and can lead to anatomic and functional anomalies in any organ system. What isn't known is how isomerism affects characteristics of the initial birth hospitalization. Data from the Kids Inpatient Database was used to compare the birth hospitalization between those with and without isomerism. A total of 4,442,985 admissions were included in the analysis. Of these, 1,6624 $(0.04 \%)$ had isomerism. Patients with isomerism had increased length and cost of hospital stay when compared to those without. Comorbidities were more likely in those with isomerism. Need for diagnostic procedures, surgeries, and extracorporeal membrane oxygenation was also greater in those with isomerism. Inpatient mortality was also found in a greater proportion of those with isomerism. Isomerism mediates differences in the birth admission.
\end{abstract}

Volume 7 Issue 2 - 2017

Rohit S Loomba

Cincinnati Children's Hospital Medical Center, USA

Correspondence: Rohit S. Loomba, MD, Cincinnati Childrens Hospital Medical Center, 3333 Burnet Avenue, Cincinnati, $\mathrm{OH}$, 45229, USA, Email loomba.rohit@gmail.com

Received: August 10,2017| Published: September 06, 2017

Keywords: heterotaxy, isomerism, birth, prematurity

\section{Introduction}

Isomerism, also known as heterotaxy, is a rare clinical entity which affects approximately 1 in 10,000 live births. ${ }^{1-3}$ The essence of isomerism has been demonstrated to be the mirror imaged findings in the thorax such that there are often two morphologically similar bronchuses, two morphologically similar lungs, and two morphologically similar atrial appendages. Abdominal arrangement in the setting of isomerism appears to be random. Nearly every organ system can be impacted in the setting of isomerism in an anatomic and/ or functional manner. Isomerism can be segregated into the subsets of right and left based on the morphology of the atrial appendages. Those with right isomerism will often have eparterial bronchuses bilaterally, trilobed lungs bilaterally, and absence of a spleen. Those with left isomerism will often have hyparterial bronchuses bilaterally, bilobed lungs bilaterally, and presence of multiple spleens. Congenital malformations of the heart, intestinal malrotation, and arrhythmias are common in both right and left isomerism. ${ }^{4-8}$

Many patients with isomerism will require cardiac surgery, some requiring staged surgery as they proceed along the functionally univentricular pathway. Isomerism has been noted to impact postoperative outcomes and general morbidity and mortality. ${ }^{9-11}$ What has not been previously described are the characteristics of the initial birth hospitalization in those with isomerism compared to those without. We used the Kids Inpatient Database to characterize and compare birth hospitalizations in those with and without isomerism. We hypothesized that isomerism would increase the neonatal admission's length, cost, and mortality.

\section{Methods}

A cross-sectional study was conducted using the Kids Inpatient Database maintained by the Agency for Healthcare Research and Quality and the Healthcare Cost and Utilization Project. Only inhospital births were included in the final analysis. All in-hospital births were then separated by the presence or absence of isomerism. Comorbidities were then identified by international classification of diseases, ninth revision codes. Univariate analysis was conducted utilizing chi-square or fisher exact analysis for categorical variables and Mann-Whitney-U test for continuous variables. Linear regression was then done to identify independent risk factors associated with greater length of stay as well as greater cost of hospitalization. Logistic regression was then conducted to identify independent risk factors associated with in-hospital mortality.

\section{Results}

A total of 4,442,984 in-hospital birth admissions were included in the analysis. Of these, 1,624 (0.04\%) had isomerism. Characteristics and univariate analysis is outlined in Table 1 . Prematurity was noted with less frequency in those with isomerism (odds ratio 0.871, $95 \%$ confidence interval 0.766 to 0.990 ). There was no statistically significant difference in the proportion of still births between the two groups. All congenital malformations of the heart were found to be more prevalence in those with isomerism when compared to those without. The most frequent was double outlet right ventricle found in $6.9 \%$ of those with isomerism followed by atrioventricular septal defect found in $6.0 \%$ of those with isomerism. Arrhythmia $(0.7 \%$ of those with isomerism), heart failure (1.3\% of those with isomerism), and cardiac arrest $(0.5 \%$ of those with isomerism), were more frequent in those with isomerism as well. Noncardiac malformations were also noted with greater frequency in those with isomerism. Those with isomerism required a great number of procedures prior to discharge. They were more likely to require intubation and mechanical ventilation, require extracorporeal membrane oxygenation, undergo echocardiograms, and undergo cardiac magnetic resonance imaging (Table 1).

Regression analysis demonstrated that isomerism was an independent risk factor for greater length of stay, increasing the hospitalization by approximately 1.5 days $(\mathrm{p}<0.001)$. Isomerism was also an independent risk factor for greater cost of hospitalization, increasing the cost of by approximately 42,088 US dollars ( $p<0.001)$. Isomerism was also an independent risk factor for inpatient mortality (odds ratio $2.503,95 \%$ confidence interval 1.898 to 3.300 ). The frequency of inpatient mortality in those with isomerism was $9.8 \%$.

\section{Discussion}

This analysis demonstrates that isomerism impacts the characteristics of in-hospital birth admissions, increasing the length of stay, cost of hospitalization, and risk of mortality. This 
is not unexpected as those with isomerism often have congenital malformations in multiple organ systems. Functional complications are also present in several organ systems. As such, these patients require additional diagnostic evaluation and intervention. Interestingly, neither premature birth nor still birth was noted in greater proportion in those with isomerism. The proportion of cardiac and noncardiac malformations and procedures such as echocardiograms noted in this analysis are not representative of the true proportion noted in isomerism overall as not all patients are diagnosed with isomerism prenatally or during their birth admission. Comparison to previous studies cannot be really done as characteristics of neonatal admissions in those with isomerism have not really been investigated as such. This data characterizes birth admissions for those with isomerism, highlighting increased morbidity and mortality which highlights the need for increased vigilance in these patients during this early period of life.

Table I Categorical data presented as absolute frequency and percentage. Continuous data presented as median and range

\begin{tabular}{|c|c|c|c|c|}
\hline & $\begin{array}{l}\text { No Isomerism } \\
(\mathrm{N}=4,441,342)\end{array}$ & Isomerism $(\mathbf{N}=\mathrm{I}, \mathbf{6 4 2})$ & $\begin{array}{l}\text { Odds Ratio (95\% } \\
\text { Confidence Interval) }\end{array}$ & P-Value \\
\hline \multicolumn{5}{|l|}{ Race } \\
\hline White & $\mathrm{I}, 855,090(5 \mathrm{I} .5)$ & $631(47.0)$ & & \\
\hline Black & $579,739(16.1)$ & $207(15.4)$ & & \\
\hline Hispanic & $770,152(21.4)$ & $339(25.2)$ & -- & 0.001 \\
\hline Asian or Pacific Islander & $165,333(4.6)$ & $71(5.3)$ & & \\
\hline Native American & $24,386(0.7)$ & $15(I . I)$ & & \\
\hline Other & $206.286(5.7)$ & $80(6.0)$ & & \\
\hline Heart failure & $2,462(0.1)$ & $22(I .3)$ & 24.485 (16.047 to 37.360$)$ & $<0.001$ \\
\hline Acute kidney injury & $4,744(0.1)$ & $25(1.5)$ & | $4.459(9.73 \mid$ to 21.485$)$ & $<0.001$ \\
\hline \multicolumn{4}{|c|}{ 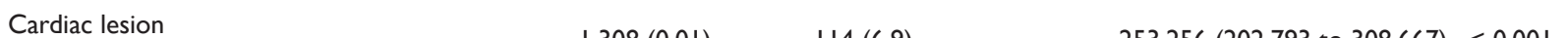 } & $<0.001$ \\
\hline Double outlet right ventricle & $2,706(0.1)$ & $98(6.0)$ & $104.112(84.592$ to 128.136$)$ & $<0.001$ \\
\hline Atrioventricular septal defect & $105(0.01)$ & $5(0.3)$ & $129.192(52.607$ to $3|7.27|)$ & $<0.001$ \\
\hline Partial anomalous pulmonary venous connection & $471(0.01)$ & $33(2.0)$ & $193.377(135.414$ to 276.150$)$ & $<0.001$ \\
\hline Total anomalous pulmonary venous connection & $537(0.01)$ & $10(0.6)$ & $50.672(27.057$ to 94.897$)$ & $<0.001$ \\
\hline Coronary artery anomaly & $4,299(0.1)$ & $40(2.4)$ & 25.771 (18.804 to 35.318$)$ & $<0.001$ \\
\hline Tetralogy of Fallot & $\mathrm{I}, 763(0.01)$ & $59(3.6)$ & 93.856 (72.076 to 122.217$)$ & $<0.001$ \\
\hline Transposition of the great arteries & $81(0.01)$ & $5(0.3)$ & $167.472(67.785$ to $4 \mid 3.760)$ & $<0.001$ \\
\hline Congenitally corrected transposition & $\mathrm{I}, 063(0.01)$ & $47(2.9)$ & I 23.088 (9I.529 to I65.527) & $<0.001$ \\
\hline Pulmonary atresia & $942(0.01)$ & $18(I .1)$ & $52.247(32.690$ to 83.502$)$ & $<0.001$ \\
\hline Tricuspid atresia & $74 I(0.01)$ & $5(0.3)$ & 18.304 (7.586 to 44.165$)^{\prime}$ & $<0.001$ \\
\hline Ebstein anomaly & $2,530(0.1)$ & $32(1.9)$ & 34.871 (24.523 to 49.587 ) & $<0.001$ \\
\hline $\begin{array}{l}\text { Hypoplastic left heart syndrome } \\
\text { Truncus arteriosus }\end{array}$ & $720(0.01)$ & $4(0.2)$ & $|5.08|(5.63 \mid$ to 40.286$)$ & $<0.001$ \\
\hline Arrhythmia & $\mathrm{I}, 976(0.0 \mathrm{I})$ & II (0.7) & I5.I52 (8.36I to 27.460$)$ & $<0.001$ \\
\hline Pancreatic anomaly & $207(0.01)$ & $5(0.3)$ & 65.531 (26.955 to I59.316) & $<0.001$ \\
\hline Atresia of the small intestine & $4,690(0.1)$ & $14(0.9)$ & 8.135 (4.803 to 13.777$)$ & $<0.001$ \\
\hline Atresia of the large intestine & $5,021(0.1)$ & $43(2.6)$ & $23.760(17.529$ to 32.206$)$ & $<0.001$ \\
\hline Biliary atresia & $224(0.01)$ & $4(0.2)$ & 48.416 (I7.992 to I30.283) & $<0.001$ \\
\hline Intestinal malrotation & $\mathrm{I}, 630(0.01)$ & $49(3.0)$ & $83.78 \mid$ (62.792 to III.787) & $<0.001$ \\
\hline Cardiac arrest & $681(0.01)$ & $8(0.5)$ & 31.926 (I5.874 to 64.206$)$ & $<0.001$ \\
\hline Extracorporeal membrane oxygenation & $719(0.01)$ & $23(2.0)$ & 75.684 (49.770 to II5.09I) & $<0.001$ \\
\hline Still birth & $2,813(0.1)$ & $3(0.2)$ & $2.888(0.930$ to 8.969$)$ & 0.055 \\
\hline Premature birth (Prior to 37 weeks gestation) & $851,413(19.2)$ & $281(17.1)$ & 0.871 ( 0.766 to 0.990$)$ & 0.034 \\
\hline Length of hospital stay (days) & $3(0$ to 656$)$ & $3(0$ to 276$)$ & -- & 0.002 \\
\hline Cost of hospitalization (US dollars) & $\begin{array}{l}3,223 \text { (I to } \\
5,522,992)\end{array}$ & II,I53 (73 to $4, \mid 76,035)$ & -- & $<0.001$ \\
\hline Number of procedures prior to discharge & I $(0$ to 34$)$ & $2(0$ to 30$)$ & -- & $<0.001$ \\
\hline Intubation with mechanical ventilation & $497,430(11.2)$ & $566(34.5)$ & $4.186(3.712$ to $4.72 I)$ & $<0.001$ \\
\hline Echocardiogram & $66,620(1.5)$ & $189(1 \mid .5)$ & $8.413(7.034$ to 10.061$)$ & $<0.001$ \\
\hline Cardiac magnetic resonance imaging & $443(0.01)$ & $7(0.4)$ & $153.303(61.912$ to 379.601$)$ & $<0.001$ \\
\hline Inpatient mortality & $45,858(1.0)$ & $161(9.8)$ & $10.417(8.851$ to 12.260$)$ & $<0.001$ \\
\hline
\end{tabular}

\section{Acknowledgments}

None.

\section{Conflicts of interest}

The authors declare no conflicts of interest.

\section{References}

1. Loomba RS. Prevalence of isomerism from a European registry:live births, fetal deaths, and terminations of pregnancy. Congenital anomalies. 2016;56(6):256-257.
2. Evans WN, Acherman RJ, Restrepo H. Heterotaxy in southern Nevada:prenatal detection and epidemiology. Pediatric cardiology. 2015;36(5):930-934.

3. Loomba RS, Hlavacek AM, Spicer DE, et al. Isomerism or heterotaxy:which term leads to better understanding? Cardiol Young. 2015;25(6):1035-1043.

4. Loomba R, Shah PH, Anderson RH. Fetal Magnetic Resonance Imaging of Malformations Associated with Heterotaxy. Cureus. 2015;7(5):e269.

5. Loomba RS, Ahmed MM, Spicer DE, et al. Manifestations of bodily isomerism. Cardiovasc Pathol. 2016;25(3):173-180. 
6. Loomba RS, Shah PH, Anderson RH, et al. Radiologic consideration in heterotaxy:The need for detailed anatomic evaluation. Cureus. 2016;8(1):e470.

7. Loomba RS, Aggarwal S, Gupta N, et al. Arrhythmias in Adult Congenital Patients With Bodily Isomerism. Pediatr Cardiol. 2015;37(2):330-337.

8. Loomba RS, Willes RJ, Kovach JR, et al. Chronic Arrhythmias in the Setting of Heterotaxy: Differences between Right and Left Isomerism. Congenit Heart Dis. 2015;11(1):7-18.

9. Takeuchi K, McGowan FX Jr, Bacha EA, et al. Analysis of surgical outcome in complex double-outlet right ventricle with heterotaxy syndrome or complete atrioventricular canal defect. Ann Thorac Surg. 2006;82(1):146-152.
10. Silvilairat S, Pongprot Y, Sittiwangkul R, et al. Factors influencing survival in patients after bidirectional Glenn shunt. Asian Cardiovasc Thorac Ann. 2008;16(5):381-386.

11. Loomba RS, Nijhawan K, Anderson R. Impact of Era, Type of Isomerism, and Ventricular Morphology on Survival in Heterotaxy:Implications for Therapeutic Management. World J Pediatr Congenit Heart Surg. 2016;7(1):54-62. 